\title{
The transformation of trust in China's alternative food networks: disruption, reconstruction, and development
}

\author{
Raymond Yu Wang ${ }^{1}$, Zhenzhong $\mathrm{Si}^{2},{\text { Cho Nam } \mathrm{Ng}^{3} \text { and Steffanie Scott }}^{2}$
}

\begin{abstract}
Food safety issues in China have received much scholarly attention, yet few studies systematically examined this matter through the lens of trust. More importantly, little is known about the transformation of different types of trust in the dynamic process of food production, provision, and consumption. We consider trust as an evolving interdependent relationship between different actors. We used the Beijing County Fair, a prominent ecological farmers' market in China, as an example to examine the transformation of trust in China's alternative food networks. We argue that although there has been a disruption of institutional trust among the general public since 2008 when the melamine-tainted milk scandal broke out, reconstruction of individual trust and development of organizational trust have been observed, along with the emergence and increasing popularity of alternative food networks. Based on more than six months of fieldwork on the emerging ecological agriculture sector in 13 provinces across China as well as monitoring of online discussions and posts, we analyze how various social factors - including but not limited to direct and indirect reciprocity, information, endogenous institutions, and altruism - have simultaneously contributed to the transformation of trust in China's alternative food networks. The findings not only complement current social theories of trust, but also highlight an important yet understudied phenomenon whereby informal social mechanisms have been partially substituting for formal institutions and gradually have been building trust against the backdrop of the food safety crisis in China.
\end{abstract}

Key Words: alternative food networks; China; food systems; social theory; trust transformation

\section{INTRODUCTION}

Food safety issues in China have received much scholarly attention (Wang et al. 2008, Klein 2009, 2013, Veeck et al. 2010, Yan 2012, Yang 2013), yet few studies systematically examined this matter through the lens of trust. In particular, little is known about the transformation of different types of trust in the dynamic process of food production, provision, and consumption. In previous social sciences literature, trust has been commonly viewed as a perception of individuals, organizations, or institutions. Research on trust tends to explore socialpsychological features that might contribute to the establishment of trust. For instance, some scholars focus on sources and interpretations of interpersonal and interorganizational trust (Lorenz 1988, Putnam 1993, Fukuyama 1995, Nooteboom et al. 1997, Lane and Bachmann 1998, Uslaner 2002, Rothstein 2005); others explore individuals' perceptions of authorities and seek to understand origins and the process of establishment of institutional trust (Levi and Stoker 2000, Mishler and Rose 2001, Bachmann and Inkpen 2011). In the field of food studies, consumers' trust in food has been on the research agenda in Europe over the past two decades, with a focus on variations in and explanations of trust in different cultural and institutional contexts (Berg 2004, Kjærnes 2006, Fritz and Fischer 2007, Lobb et al. 2007). However, trust is rarely interrogated as a multidimensional behavior from an evolutionary perspective. In other words, little academic attention is paid to the transformation of different types of trust in a dynamic process (Chen 2013). To a great extent, this research gap constrains scholars' knowledge about how trust evolves in complex socioeconomic contexts and how the transformation of trust might influence long-term social interactions among a variety of actors. To respond to this research gap, this paper uses trust in food as a lens to illustrate processes of, and conditions for, the transformation of trust in China's emerging alternative food networks (AFNs).$^{[1]}$ By viewing trust as a dynamic, multifaceted concept, it seeks to draw social scientists' attention to a significant and yet poorly understood phenomenon in which a series of informal institutions have been partially substituting for formal institutions, building trust and gradually reshaping the dynamics of interactions between food producers and consumers against the backdrop of food safety crisis in China.

A food system usually refers to the process of food production, processing, transportation, consumption, and waste disposal (Ericksen 2008). In the era of rapid modernization, an implicit trust is placed in a set of formal institutions that ensure the quality of food when urban residents purchase food from conventional retail outlets such as wet markets, convenience stores, and supermarkets. The conventional food systems in the West have led to not only efficiency and economic benefits but also various crises (Sonnino and Marsden 2006). Critical reflections by rural sociologists and human ecologists unveiled their social and geographical disembeddedness, their destruction of the relationship between people and food, and their social and environmental consequences (Feagan 2007, Milestad et al. 2010). In response to the crises, a group of AFNs emerged in the West in the 1990s or earlier (Goodman et al. 2012). Common examples of AFNs are farmers' markets, Community-Supported Agriculture (CSA),${ }^{[2]}$ buying clubs, community gardens, and public procurement programs ( $\mathrm{Si}$ et al. 2014). Fostering the reconnection between people and food and the re-embedding of food within social and geographical relations, these AFNs demonstrate a significantly different logic in challenging the conventional food systems that are highly industrialized and globalized. 
In China, the rethinking and criticism of conventional food systems accompanied by the emergence of AFNs (Shi et al. 2011a, Scott et al. 2014, Si et al. 2014) were triggered largely by food safety scandals in the past few years, symbolized by the melamine formula scandal in 2008. Agrifood scholars have argued that consumers purchasing food at these alternative venues are reconnecting and building a new trust relationship with individual vendors and food production groups (Jarosz 2000, Whatmore et al. 2003, Kirwan 2004, Holloway et al. 2006, Wiskerke 2009, Freyer et al. 2014). The shift of some Chinese consumers from conventional food retail venues to AFNs thus not only serves as a lens through which food safety issues can be observed, but also offers a unique case to examine the transformation of trust in the specific social and institutional settings of China.

We took the most prominent ecological farmers' market in China, the Beijing Country Fair (BCF), as a case to interrogate the evolution in consumers' patronage of different food venues, with a particular focus on informal institutions and social relations that have been facilitating the transformation of trust and the emergence and prosperity of AFNs.

\section{THE CONCEPTUALIZATION OF TRUST}

The conceptualization of trust has been a contentious topic. Some posit that trust is composed of background expectations that are part of a "world known in common" (Schuetz 1945) and constitutive expectations that are portrayed by formal and informal rules specifying alternative actions regardless of one's individual desires (Garfinkel 1963, Zucker 1986, Putnam 1995, Lane and Bachmann 1998, Rousseau et al. 1998); others emphasize that trust is associated with one's willingness to take a risk and be vulnerable to another. In essence, it is risky to place trust in another actor because the trustor would suffer a loss if his or her expectations for cooperation were not fulfilled (Johnson-George and Swap 1982, Mayer et al. 1995, Schoorman et al. 2007). However, in terms of broad theoretical and empirical research, it is important to delineate boundaries between trust as an aspect of social relationships and trust as a consequence of social norms and regulations. More specifically, it should be clearly recognized that trust itself is a choice of action or a state of perception. We argue that trust, in fact, can be derived from various social, economic, and political factors that are difficult to thoroughly include in one definition. Therefore, the definition of trust should rest on features that characterize a unique interdependent relationship rather than on its sources and foundations.

In a general socioeconomic context, we adopted Coleman's (1990) definition of trust, which includes four defining characteristics. First, trust involves a minimum of two parties, among whom one party, i.e., the trustor, can choose whether or not to voluntarily place trust on the other party, i.e., the trustee. The trust here placed on the trustee could be in various forms including, but not limited to, money, time, effort, support, affection, and so forth. Second, after trust is placed, the trustee can choose to honor or abuse the trust. Either way, the trustor has no control over the action of the trustee. Third, there is a time lag during which the trustor has delivered his or her trust and yet is not aware of the behavior of the trustee. Last, the trustor is better off to place trust than not to do so if the trustee is trustworthy; however, the trustor is worse off should the trustee be untrustworthy, assuming both parties are purposive actors. This behavioral description of trust not only contains critical components of the above mentioned definitions, i.e. willingness to accept vulnerability and expectations of positive behavior from another, but also leaves space for further investigations of factors that might affect the behavior of the actors involved.

In addition to its diverse definitions, the classification of trust is another controversial topic. Once again, many researchers highlight the sources of trust and classify it as process based, characteristic based, competence based, or institutionally based (Zucker 1986, Lindgreen 2003, Edelenbos and Eshuis 2012). However, these classifications still face the conundrum that pertains to distinguishing sources of trust before carrying out any substantial analysis. In the field of food studies, some scholars argue that trust is a concept at the individual or interpersonal level (Berg 2004). Others focus on trust in institutions (Chen 2008, de Jonge et al. 2008). Freyer et al. (2014) identified three types of consumer trust in organic products: uninformed organic consumers, informed organic consumers, and informed and engaged consumers. This classification establishes linkages between trust and consumers' motivation, habits, and perceptions; however, it is inadequate for understanding the transformation of different types of trust in a broader context where trust relationships are more complex and trust is placed in divergent trustees. Based on the identity of trustees and previous work by Edelenbos and Eshuis (2012) and Freyer et al. (2014), we propose a categorization of trust as shown in Table 1.

Table 1. An object-oriented classification of trust.

\begin{tabular}{|c|c|}
\hline Type of Trust & Descriptions \\
\hline Individual trust & $\begin{array}{l}\text { The trust that a trustor places in an individual. The } \\
\text { key feature that sustains individual trust is an } \\
\text { interpersonal relationship that is usually based on } \\
\text { face-to-face contacts and mutual acquaintance. }\end{array}$ \\
\hline $\begin{array}{l}\text { Organizational } \\
\text { trust }\end{array}$ & $\begin{array}{l}\text { The trust that a trustor places in an organization, } \\
\text { which could be a group, an enterprise, or a } \\
\text { nonprofit association. This trust relationship is } \\
\text { attributable to the ability, benevolence, and } \\
\text { integrity of an organization. }\end{array}$ \\
\hline $\begin{array}{l}\text { Institutional } \\
\text { trust }\end{array}$ & $\begin{array}{l}\text { The trust that a trustor places in formal rules and } \\
\text { institutional arrangements. The key feature that } \\
\text { sustains institutional trust is a relationship } \\
\text { involving multilevel interactions. This implies that } \\
\text { one actor trusts institutions (i.e., contracts, } \\
\text { regulations, social conventions) rather than another } \\
\text { individual or organization. Institutional trust is } \\
\text { usually based on confidence in an institutional } \\
\text { actor's (e.g., regulatory agencies, governments, } \\
\text { authorities) intention, capability, fairness, } \\
\text { consistency, and efficiency of enforcing established } \\
\text { rules. }\end{array}$ \\
\hline
\end{tabular}

We do not intend to engage in the grand conceptual discussion of trust classification, but rather to emphasize that trust can be placed in different objects at different levels; therefore, it could better serve the following analysis on the issue of trust transformation in China's AFNs. The main reason to adopt this object-oriented classification of trust is that individual and collective behaviors (i.e., whom one chooses to collaborate with 
and at which venue one chooses to carry out his or her socioeconomic exchanges) are easier to observe in complex settings. Supported by observable phenomena and empirical data, the conceptual framework in this paper is more compatible with a heuristic way of investigating conditions for the transformation of trust.

\section{RESEARCH METHODS AND DATA COLLECTION}

We drew from a larger research project conducted between 2010 and 2014 on China's emerging ecological agriculture sector. This project examined the typology, organizational structures, governance, and socioeconomic embeddedness of the ecological agriculture sector, including certified and uncertified organic and "green food" ${ }^{[3]}$ and various types of AFNs. The research team collectively conducted 127 in-depth interviews over 6 months of fieldwork in Liaoning, Beijing, Shandong, Henan, Anhui, Jiangsu, Shanghai, Zhejiang, Sichuan, Chongqing, Guangxi, Fujian, and Hainan. Informants were identified through various contacts including academic organizations, nongovernmental organizations, CSA networks, and government referrals. They were key players in the ecological agriculture sector with diverse backgrounds: entrepreneurs who run organic and green food farms, initiators of AFNs, representatives of organic certification agencies, government officials, consumer associations, nongovernmental organizations, and researchers (see Table 2).

Table 2. Number of interviews conducted with different types of interviewees.

\begin{tabular}{lc}
\hline \hline Type of interviewee & Number of interviews ${ }^{\dagger}$ \\
\hline Managers and workers on ecological farms & 42 \\
Managers of farmers' markets & 4 \\
Representatives of buying clubs & 3 \\
People renting plots for recreational & 5 \\
gardening & \\
Governmental officials & 20 \\
Researchers & 32 \\
Organic certification agencies & 11 \\
Directors and employees of NGOs & 10 \\
Total & 127 \\
\hline
\end{tabular}

${ }^{\dagger}$ Some interviews were conducted with the same interviewee.

Although the primary focus of our research was the case of the $\mathrm{BCF}$, we drew upon information from a much wider array of sources across China, which include 3 in-depth semistructured interviews with $\mathrm{BCF}$ market managers, on-site observations from 3 visits to $\mathrm{BCF}$ markets, 12 in-depth interviews with vendors of the BCF and Shanghai Nonghao farmers' market, and interviews with organizers of 3 consumer organizations. These interviews were conducted in April and December 2012 and March 2013. Interviews with market managers covered questions about the establishment and operation of the farmers' market, general features and motivations of their customers, their perceptions of food safety and trust issues, approaches to build the solidarity among their vendors and to maintain their customer bases, and the wider implications of farmers' markets for China's food system. Interviews with market vendors, mainly CSA farmers, focused on the operation of CSAs, their ecological farming practices, policy impacts on their operations, and various strategies they used to maintain trust relationships with other vendors and with their customers. Interviews with consumer organizations, i.e., buying clubs, covered the establishment of the organization, consumers' food safety concerns, consumers' perceptions of trustworthiness of food sources, why they purchased food from certain sources, their descriptions of personal connections with food producers, and so forth. Therefore, findings presented in this paper are not confined to observations and interviews at the BCF. To enhance our understanding of consumer perspectives, reports from public media and newsletters of CSA farms and the BCF were also reviewed. Additional information was acquired by monitoring online discussions and posts mainly from the BCF's official account on Weibo, the most popular microblog in China.

\section{THE DISRUPTION OF INSTITUTIONAL TRUST: UNDERSTANDING THE TRUST RELATIONSHIP BETWEEN CUSTOMERS AND INSTITUTIONS}

The analysis begins with a discussion about the disruption of institutional trust. Food used to be an innocent sphere of Chinese urban consumers' daily lives. Although food safety incidents emerged much earlier and recurred consistently over the past few decades in China, this situation has changed dramatically with the steady increase of food safety scandals in the past decade. Most prominently, in 2008, the Sanlu group, a leading giant in the Chinese dairy business, was found intentionally manufacturing melamine-tainted baby formula, which resulted in 6 deaths and nearly 300,000 cases of children suffering from kidney problems (Yang 2013). The melamine-tainted milk powder scandal, preceded and followed by a series of other food safety incidents, ${ }^{[4]}$ constituted large-scale production and circulation of hazardous foods. These cases revealed serious problems in conventional food supply chains and therefore caused a widespread disruption of trust in conventional food retail venues and regulatory institutions (Yan 2012).

To understand food safety issues in China, several previous studies have adopted Ulrich Beck and Anthony Giddens' depiction of "risk society" (Giddens 1991, Beck 1992). The notion of risk society is characterized by social anxiety resulted from incalculable, unpredictable, and uncontrollable impacts of scientific and technological advancement in postindustrialized countries. In light of the theory of risk society, these studies analyzed Chinese consumers' behavior and attitudes toward food safety issues and further incorporated local characteristics into the theory that was built in the context of western societies (Veeck et al. 2010, Yan 2012, Klein 2013). However, the risk society framework is inadequate for understanding consumers' response to rules and regulations that are supposed to minimize risks of modernity and ensure food safety (Kjærnes 2010). In China, a series of food quality certification standards, including "hazardfree food," green food, and organic food, have been established to cope with the increase of food safety scandals (see Scott et al. 2014). In the 1990s and 2000s, a set of food safety laws and regulations was enacted. By 2013, there were about 2000 national food regulations, including the Food Safety Law enacted in 2009, and 2900 industry-based regulations (Agres 2013). A new administrative system was established at the national level to define, coordinate, and supervise the responsibilities and actions of each governmental agency in food safety governance (Jia and Jukes 2013). Food safety offenders faced much more severe punishment. However, food safety problems persist. Based on our 
interviews with consumers and vendors, and data collected from Weibo, a significant decline in the level of institutional trust was observed. This disruption of institutional trust is mainly reflected by two aspects of consumers' and food producers' activities.

One is that the general public, particularly the so-called "middle class," ${ }^{[5]}$ has shown a propensity to purchase food from AFNs rather than from conventional food venues. The most salient phenomenon is that products labeled as green food or organic food fail to convince a large number of customers that they truly meet the "green" or "organic" standards. The majority of our interviewees expressed their concerns over what these labels might imply about the production of the food. For instance, during a 27 May 2012 interview, a woman at the Shanghai Nonghao Farmers' Market explained, "All the certified organic food is fraudulent. As long as [farms] give [certification agencies] money, you can get certified." A member of a buying club in Beijing commented in a 9 April 2012 interview, "The adulteration of organic certification is very common. It's so hard to tell whether it is truly organic or not so I simply don't trust them ... I heard that sometimes before inspection, certification agencies will call the farm, ask them to prepare for the inspection (take away all the chemical stuff)." Moreover, consumers' distrust of certified organic food is widely reflected in mass media reports (Shao and Yang 2014). Some even claim that it is the internal competition among regulatory agencies and uncoordinated institutional responsibilities in a fragmented authoritarian regime that prevented food administration agencies from successfully fulfilling their responsibilities (Chen 2009, Pei et al. 2011, Yan 2012). These comments indicate that the interviewees were skeptical about the credibility of the food certification system, and also point to the crisis of governance. They questioned the accountability of the Chinese authorities that initiated, promoted, and supervised the food certification system (Klein 2009).

The other aspect of the disruption of institutional trust is reflected by the fact that market vendors, most of whom run CSA farms, are not motivated to have their products certified by formal institutions either, because, they argued, the certification of food would increase their costs. Moreover, they were not convinced that the certification was a necessary assurance of the quality of their food or could attract more customers. When explaining during a 6 April 2012 interview why he did not pursue organic certification, a green food farm operator in Dalian, Liaoning province, noted that because of the challenge of finding organic seeds, organic farms claiming to be organic may not really be so. Another CSA farmer in Beijing commented during a 1 April 2012 interview that there were so many fake organic foods in the market that the government had to "clean up 'organic." A Beijing CSA farmer and vendor at the BCF claimed during a 31 March 2012 interview that "third party certification is not as ethical as a direct trust relationship with customers." This perception was echoed by a vendor at the BCF:

I do not trust those capital intensive large-scale organic farms. In China, organic farms established with the involvement of big capital and [government] authorities are generally fake. They kidnapped the market channels, the propaganda and other information resources to promote their so-called "organic" food. But consumers have lost confidence in them.

(Interview, 9 March 2013, Beijing)
Reasons for the decline of institutional trust are complex. Previous studies suggested that some loopholes in the formal institutions made the system fail to provide safe food that consumers trust (Mol 2014). These loopholes include contradictory and overlapping regulations and laws, failure of coordination among governmental agencies, a lack of information-sharing mechanisms, inadequate participation of independent third parties, and so forth (for details see Broughton and Walker 2010, Liu 2010, Wang and $\mathrm{Hu}$ 2011, Jia and Jukes 2013, FORHEAD 2014).

Based on our fieldwork, the explosion of information is another major cause for the disruption of institutional trust. With growing media coverage of food safety issues and the development of technology that provides the general public with more access to information, most consumers build their perception of food safety problems through media rather than direct personal experiences (Yang 2013). Potential pathogenicity of abused food additives, coupled with unsanitary environments for food processing, top the headlines of Chinese news reports (Yan 2012). This leads to an exponential increase of the number of people who are exposed to food safety risks. "What can we eat?" became one of the most commonly raised questions by Chinese netizens. On 15 September 2014, we found 2,307,200 posts by searching "what can we eat" on the most popular social media in China, the microblog Weibo.

Although full transparency is curtailed by the party-state authority, Yang (2013) identified two diverging movements: namely, hegemonic practices by government and corporations to suppress free dissemination of information and counterhegemonic practices by diffused contention on Weibo to express dissent. The ramifications of this contestation are far beyond facts related to food safety problems. The information disclosed during this contestation changes the social perceptions of food safety. It has not only drawn extensive public attention, but also revealed a hidden side of food production and regulation associated with Chinese historical memories of food insecurity and authoritarian control, thus making a far-reaching impact on the decline of social and institutional trust (Veeck et al. 2010, Yan 2012).

\section{THE RECONSTRUCTION OF INDIVIDUAL TRUST: UNDERSTANDING THE TRUST RELATIONSHIP BETWEEN VENDORS AND CUSTOMERS}

Although the level of institutional trust has radically declined, food is still an indispensable part of people's daily life. It is important to understand how Chinese urban residents react to such a situation of insecurity. We argue that the pattern of food consumption among some Chinese urban residents who participate in AFNs is gradually changing. Although the trustworthiness of conventional food networks is impaired, in the past few years an increasing number of people have been motivated to purchase food through AFNs. Moreover, the establishment of these AFNs has demonstrated a reconstruction of individual trust between producers and consumers.

One should note that individual trust is not a novel concept in food transactions. It exists at wet markets, where consumers and producers have face-to-face exchanges. Since the 1990s, the food supply chain in China has changed substantially. With the modernization of food value chains, urbanites have becoming increasingly disconnected from the production of food. Trust between individuals tends to be replaced by formal institutions, 
e.g., food quality certifications, that corporatize and standardize food production. However, after the food safety scandals broke out, individual trust in food has rebounded in a small number of ecological farmers' markets and other AFNs in China in response to the food safety crisis.

Farmers' markets as a type of AFN demonstrate new characteristics compared with traditional wet markets. More than a simple place of transaction, farmers' markets nowadays emphasize "healthy" and "ecological" food production processes and other social values ( $\mathrm{Si}$ et al. 2014). Vendors at these markets are committed to ensuring the safety and quality of food. However, to convince the consumers, much effort is required to reconstruct individual trust because consumers are skeptical about whether the food is indeed safe and healthy when they are incapable of judging the quality from its appearance. In the $\mathrm{BCF}$, we observed a variety of reciprocal activities. These activities suggested that, as difficult as it might be, trust problems can be overcome through certain social mechanisms.

\section{Direct reciprocity}

Direct reciprocity is based on the concept of repeated interactions (Axelrod 1984, Diekmann 2004). The chance of another encounter between the same two individuals constitutes a "shadow of the future," which creates incentives for cooperation between the individuals. Thus cooperative strategies might prevail as long as the probability of future interactions is sufficiently high.

In empirical settings, one way to enhance direct reciprocity is to build stronger connections between vendors and customers through direct face-to-face contact to the extent that the customers have confidence in the vendors' commitment to a longterm business relationship. For example, a vendor from Heilongjiang province in northeast China whom we met at the Beijing Country Fair on 9 March 2013 provided many photos of his rice farms to demonstrate to customers that he adhered to sustainable cultivation practices. He sought to convince customers that his rice was indeed produced in a natural and relatively clean environment and he was committed to a long-term business. In addition, the solid educational background, the strong communication skills, and the unadorned personality of many CSA farmers at the BCF all have greatly contributed to the establishment of individual trust between them and their customers. Shi Yan, one of the founders of the Little Donkey Farm and the founder of Shared Harvest Farm in Beijing, is also a well-known food activist in China. She received her doctoral degree in agricultural economics at Renmin University of China. With her educational background, internship experience on an organic farm in the United States (Shi 2012), and visits to organicrelated institutions and organizations in the West, she became a poster child for publicizing the CSA model. With extensive media exposure, many customers can easily identify with and relate to her. Shi Yan stated in interviews on 11 April 2012 and 6 December 2012 that through various forms of direct communication, vendors have become reliable partners who would not jeopardize their reciprocal relationship for short-term benefits.

Another way to improve direct reciprocity is to give more control to the customers in the vendor-customer interactions. For instance, many vendors at the BCF allow customers to visit their farms without an appointment. Many farms also lease plots to customers who want to grow their own food and provide trustworthy inputs such as uncoated and non-genetically modified seeds and organic fertilizer, and technical supports ( $\mathrm{Si}$ et al. 2014). This type of control can be viewed as an assurance provided by the vendors that allows the consumers to observe, experience, and monitor daily operation and farming practices of the vendors. As a result, doubts of the customers can be alleviated.

As the market in Beijing became more popular, the 3000 customers $^{[6]}$ or more who flock to the small market venues two or three times a week made it too overcrowded for easy face-to-face communication. The original desire of the market founders to make the market a place for direct producer-consumer communication became less feasible. To compensate for the loss of direct interaction opportunities, other means were needed to bring customers and vendors together.

\section{Indirect reciprocity and information}

Despite the effectiveness of building trust via direct communications with customers, from an evolutionary perspective trust via direct reciprocity is not fully stable because it is constantly challenged by defections and random "noises" (see Fehr and Gintis 2007). Indirect reciprocity, alternatively, is another powerful mechanism to develop individual trust. The term "indirect" implies that it is beyond one's own experiences and one can use experiences obtained from a third party. Thus, the key aspects of indirect reciprocity are information and reputation (Mailath and Samuelson 2006, Nowak 2006, 2012, Sigmund 2012, Ng et al. 2013). Customers can associate their choices of food with past experiences of others who are within the scope of their social networks. In other words, indirect reciprocity provides an opportunity for customers to adjust their behavior based on information they receive. Importantly, indirect reciprocity allows the emergence and dissemination of both positive and negative information. Therefore, not only did consumers have incentives to share information with each other to avoid untrustworthy vendors, trustworthy vendors were also motivated to enhance indirect reciprocity to attract more customers and to build their loyal customer-bases.

Information about the BCF was initially passed from one customer to another. This simple yet effective way of communicating, usually referred to as word of mouth, brought the first wave of customers to the BCF (interview with the founder of the BCF, 3 April 2012, Beijing). As a customer noted, compared with organic food certification labels, he would rather trust the assessment of his close friends (see a short note from People's Daily 2012). The effects of indirect reciprocity have been further enhanced since the BCF opened an account on the most widely used microblog in China, Weibo, in 2011. Through the new form of media, word of mouth can be mediated through electronic means. This technogical development allows both vendors and customers to share information through their social networks via the internet, and it results in a significant increase in network density and information transparency. As one of the founders of the BCF noted, the BCF indeed took off in 2011 when they opened their Weibo account (interview with the founder of the BCF, 3 April 2012, Beijing). Thirty farm vendors had their Weibo accounts listed on the front page of the BCF's blog in 2014. About 20 of them participated in the market regularly in 2012, and all 
of them have their own Weibo accounts through which they maintain a close connection with their customers. The BCF's Weibo account had more than 104,000 followers as of February 2015 and is still growing rapidly. The BCF frequently posts about knowledge-sharing activities related to organic and ecological agriculture, the hours and location of upcoming markets, responses to questions from customers, recruitment of interns and volunteers, and information about market vendors and healthy food. By commenting on these posts, customers are maintaining a close communication with the market and with others.

Traditional media, i.e., television and newspapers, have also effectively facilitated the dissemination of information about the BCF. Between 2011 and 2013, 43 reports have been published on renowned media such as China Central Television, People's Daily, The Wall Street Journal, and Financial Times. For a compiled list of media reports, see the blog of the BCF (in Chinese; http://blog. sina.com.cn/s/articlelist 191854792421 1.html). These media all have a huge number of viewers and readers. Their coverage of the BCF inspired a broad discussion on food safety issues, organic farming, and healthy lifestyles among the general public, creating strong impacts on consumers' trust in the BCF.

Through indirect reciprocity, the outcomes of dyadic interactions are amplified. The behavior of a vendor not only influences the impression of a customer with whom he or she directly interacts, but also generates a reputation. The reputation of a vendor could travel through an electronic social network as well as a traditional media network and affect how other people might perceive this particular vendor, or even the entire farmers' market. Under the effects of both direct and indirect reciprocity, individual trust has been widely reconstructed and observed in the BCF.

\section{THE DEVELOPMENT OF ORGANIZATIONAL TRUST: UNDERSTANDING THE TRUST RELATIONSHIP IN THE FARMERS' MARKET AND COMMUNITY SUPPORTED ARGRICULTURE}

The BCF has undergone a period of rapid expansion in terms of its overall scale and number of customers. During the past four years, organizational trust placed by customers in the capacity, benevolence, and integrity of the BCF and CSA farms, has emerged, thrived, and further supported their expansion in Beijing. Among the 40 vendors of the BCF in 2012, about 20 were small-scale farms that operated in a CSA model. The development of organizational trust is a particularly interesting and significant outcome that has not been reported in previous food studies in China.

\section{Endogenous rules: participatory guarantee system}

The development of the BCF is associated with a set of endogenous institutional arrangements, with a key objective of building customers' trust in this newly emerged organization. These endogenous rules are established to regulate the behavior of vendors, maintain reputation of the $\mathrm{BCF}$, and ensure interests of customers.

In the case of the BCF, these endogenous rules constitute a participatory guarantee system (PGS), which refers to "locally focused quality assurance systems ... that certify producers based on active participation of stakeholders and are built on a foundation of trust, social networks and knowledge exchange"
(International Federation of Organic Agriculture Movement, Participatory Guarantee Systems, http://www.ifoam.org/fr/valuechain/participatory-guarantee-systems-pgs). The term PGS embodies a variety of alternative organic certification approaches that are different from third-party certification. However, it generally involves participation of various stakeholders to inspect farm members of a PGS system and ensure their compliance. Its basic elements are shared vision, participation, transparency, trust, learning, and horizontality, i.e., sharing of power (International Federation of Organic Agriculture Movement 2006). The BCF has been attempting to establish China's very first PGS, which is an approach for enhancing organizational trust. Their effort is reflected in the following two endeavors.

For one thing, market managers established a set of criteria for selecting potential vendors who intend to join the market. These criteria include pesticide-free and nonchemical cultivation methods, the application of combined farming techniques such as crop rotation and careful soil management, the participation of vendors in regular meetings for updates on organic farming experiences, and so forth. (For more details, see the blog [in Chinese] of the Beijing Country Farm, http://blog.sina.com.cn/ u/1918547924.) These criteria demonstrate that quality control and good reputation are the top concerns for market managers of the $\mathrm{BCF}$.

For another thing, an inspection committee was established to scrutinize activities of farms in the BCF. This inspection committee consists of a variety of members so that every key category of stakeholders (i.e., managers, vendors, customers, scholars, and nongovernmental organizations) can express their concerns and gain full access to information. Instead of being inspected by formal institutions, i.e., third-party certification agencies, farms are screened and monitored by the self-monitoring system conducted by the inspection committee. This self-certification system is represented by the Management Guidelines of the BCF drafted by market managers and vendors. It can be viewed as a form of peer pressure on all participants to maintain solidarity and trust in the group.

From a theoretical point of view, these above-mentioned endogenous rules are imposed to guarantee the quality of food produced by market vendors. As a trustee who needs to prevent potential trustors from walking away, the market adopts a strategy that increases its transparency and provides information to the trustors through various social media such as Weibo and Wechat. ${ }^{[7]}$ This can be interpreted as an investment to enhance the effects of indirect reciprocity mechanisms. The PGS, as a comprehensive set of informal institutional arrangements, creates a good reputation for the market and enable this reputation to spread through social networks, thereby successfully developing trustors' confidence in the BCF.

\footnotetext{
Altruism

In addition to endogenous rules, another unique social mechanism that has facilitated organizational trust is a "selfless" concern for the welfare of vendors, customers, and employees. This type of concern is different from reciprocal behavior in the sense that no immediate or long-term reward can be expected from this costly input. Different patterns of selfless behavior were observed during our fieldwork in Beijing. In particular, our interviewees, who were managers of the $\mathrm{BCF}$, repeatedly emphasized that they were a "big
} 
family" rather than a profit-driven company. As a grassroots organization, the $\mathrm{BCF}$ identifies itself as a social enterprise, a term that embodies social goals such as capacity building of grassroots organizations, supporting the livelihoods of smallholders, and raising environmental awareness, along with profit making. This altruistic facet also constitutes the shared vision, a key element of PGS, among stakeholders of the market. Based on these observations, we argue that altruism is an important factor for collective cooperation and organizational trust in the $\mathrm{BCF}$.

Human altruistic behaviors have received considerable academic attention from various disciplines (Fehr and Fischbacher 2003). For instance, it is well known that kinship altruism widely exists among humans (Hamilton 1963, Axelrod and Hamilton 1981, Mohtashemi and Mui 2003). We present empirical evidence that substantiates theories of cooperation and human altruism as well as complements previous studies with regard to trust in food. One might argue that the altruistic behaviors observed within the farmers' market and CSAs are fundamentally purposive actions to attract more customers or to pursue economic benefits. However, it is not our position to speculate on the intention of the managers and vendors of the BCF without sufficient socialpsychological evaluations. What we can rely on is comments, conversations, and information that we observed and collected in our fieldwork. We are convinced by the following evidence that, in addition to reciprocal behaviors, altruistic behaviors motivated by similarity or nongenetic relatedness also exist in the $\mathrm{BCF}$ and they have improved the level of organizational trust and facilitated the development of the market.

The altruistic behaviors of managers and vendors in the BCF is first reflected in the self-identification of the $\mathrm{BCF}$ as a social enterprise that aims at improving environmental and human wellbeing. Although many CSA vendors at the $\mathrm{BCF}$ are formally registered as business corporations because of legal constraints in China, their message and the culture being conveyed to the society have always put health, social justice, and environment concerns ahead of profits. To achieve this objective, the BCF actively organized public lectures in Beijing and Shanghai to promote a healthier and more environmentally friendly way of life. Some well-educated CSA farmers even used to be white-collar workers. However, they quit their seemingly decent jobs in cities to start CSA farms with a strong commitment to environmental and social values (interviews with a CSA farmer in Beijing on 31 March 2012 and two ecological rice farmers in Beijing on 5 March 2013).

Second, altruistic behaviors are demonstrated through the ways that the BCF and CSAs are managed. For instance, no charge is imposed on vendors for selling at the market. As one of the managers of the BCF told us in an interview on 3 April 2012 in Beijing, collecting entrance fees from vendors would open them up to people thinking that they were self-interested and willing to accept anyone as a vendor, thereby jeopardizing their reputation. Market managers have used a number of additional sources of revenue such as fund raising and selling hand-made food products on the market; however, collecting admission fees from vendors has never been an option. More altruistic behaviors are reflected in family activities regularly organized by CSAs for their customers. These activities not only encourage closer connections to nature, but also strengthen customers' family bonds. Blind dates are even arranged by the market and CSAs for single interns who work at CSA farms. This "parental behavior" is beyond the scope of traditional employer-employee relationships; instead, it can be interpreted as a manifestation of close relatedness between these interns and CSAs.

In general, a high level of organizational trust was observed in our fieldwork. To a great extent, the development of organizational trust is attributed to these altruistic behaviors nested in the BCF and CSAs. The reasons for the emergence and evolution of altruism are beyond the scope of this paper. Nonetheless, it is important to recognize the existence of these altruistic behaviors and their positive impacts on the development of organizational trust.

\section{DISCUSSION: IMPLICATIONS OF THE TRANSFORMATION OF TRUST}

With our first-hand evidence and analysis, we have shown how different social conditions and mechanisms have contributed to the transformation of trust (see Fig. 1). Although this paper focuses on the specific case of the BCF, our observations on the transformation of trust patterns are significant for a wider understanding of China's changing food systems in the era of food safety crisis. We make this assertion for a number of reasons.

Fig. 1. The transformation of trust in China's alternative food networks

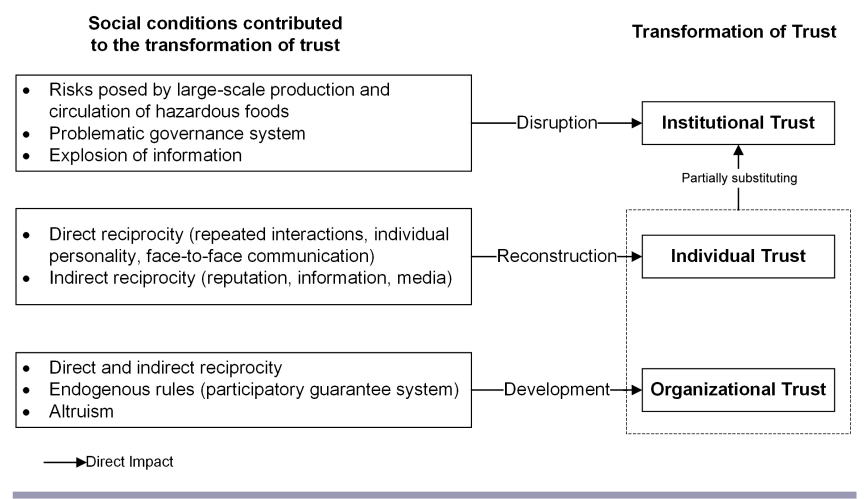

First, this research is drawn from a broader, nationwide study of the emergence of AFNs and the rapidly developing ecological agriculture sector in China. Rather than being an isolated case, the BCF is an example of emerging AFNs (see Schumilas 2014, Scott et al. 2014, Si et al. 2014, Si 2015) that are fostered by individual trust and organizational trust. In just six years, more than 300 CSA farms emerged in China and the number is still growing rapidly (C. W. Cheng, Food safety and social movement [title translated from the Chinese], http://goo.gl/Xe75QI). Farmers' markets have also emerged in other cities across China, including Shanghai, Tianjin, Xi'an, Guangzhou, Nanjing, Chengdu, Chongqing, and Hangzhou. A well-established network among, and an increasingly influential new trust relationship within, these CSAs and farmers' markets have become a nontrivial force in China's food systems. Second, the success of the BCF and many other farmers' markets and CSA farms across the country demonstrate the crisis in institutional trust that the conventional food system has relied on. In this way, 
our case study offers an effective lens through which to observe an evolving process of transformation in trust relationships. Third, although the BCF case is small, it symbolizes an alternative voice to the mainstream industrial-oriented food system in China. This "otherness" represents a new space to ask questions about, and offers new possibilities to amend, the troubling food safety issues in China. Although most current food safety literature about China focuses on the governance of conventional producers or formal regulatory institutions, this paper sheds light on critical, yet understudied, relationships of trust in which strong, informal institutions are partially substituting for weak, formal rules.

Our observations regarding the transformation of trust in AFNs have profound implications for future studies of China's food system and food policies. The transformation of trust demonstrates a changing pattern of food production, distribution, and consumption in China. This complex process embodies not only the emergence and spread of AFNs but also the industrialization of the food sector. The diversification of trust in food with the enhancement of individual trust and organizational trust in the current food system demands further research. Moreover, new food policies must take account of these changing dynamics in the food system. In China, the conventional approach to coping with food safety crises has been centered on strengthening the food safety regulatory regime (Tam and Yang 2005). Although regulation of formal regulatory institutions yields tangible results, this conventional approach is mainly confined to large-scale food industries.

In this paper we highlight the transformation of trust in fastdeveloping AFNs. Such "alternativeness" suggests that food safety problems may not be resolved solely by stringent formal regulations on industrialized food producers. Some endogenous risks are nested in the conventional food system. As Schneider (2014) argues, agri-industrialization might be the problem rather than the solution to the crisis that we see in China (see also Huang 2011). Excessive use of synthetic fertilizer and chemicals associated with agri-industrialization have not only degraded and polluted the soil and waterways but also resulted in heavy metal contamination and chemical residues in fresh produce, which eventually impaired the public's confidence in food safety (Han 2007, FORHEAD 2014, Lu et al. 2015). Intensification of the meat industry has also led to excessive use of hormones and antibiotics, and accelerated the spread of diseases, which has increased food safety risk (McDonald and Iyer 2008, Li 2009, Sharma et al. 2014). The current proindustrialization food policies that promote the vertical integration of smallholders and encourage capital penetration in the food sector need to incorporate alternative ideas and models for solving the food safety crisis. A food policy that facilitates the establishment of not only institutional trust but also individual trust and organizational trust will be beneficial. Potential strategies include supporting public education about food and encouraging the development of AFNs.

Furthermore, this study has implications for possible policy changes. It is important to explore ways to coordinate civil society-initiated PGS and formal food regulatory institutions. Second, we should explore how powerful informal institutions facilitated by civil society should be incorporated into formal policy-making processes. The impacts of bottom-up social organizations on China's food systems warrant further academic and policy attention. Nongovernmental organizations in the West such as food policy councils and roundtables (e.g., the Toronto Food Policy Council; see Welsh and MacRae 1998, Marsden and Franklin 2013) exemplify how the gap between civil society groups and policy makers can be bridged.

Meanwhile, it is important to note that our observations of the transformation of trust in food are largely confined to participants in AFNs in China. The nascent AFNs such as CSA farms and farmers' markets are still too marginal to transform the mainstream food system. Although research about consumers at these AFNs is limited, our interviews and other existing studies show that consumers purchasing through these alternative venues are mainly middle-class urbanites and people with special health concerns, e.g., expectant mothers and people with cancer. However, for some customers, the BCF is merely a trendy venue for leisure and entertainment. Thus, more research needs to be devoted to the analysis of people who shop at these AFNs, in particular to the effects of social stratification on consumers' shopping patterns. Different hierarchies within consumer groups might shape the ways in which trust in food is encountered (Klein 2013). It is too early to extend the notion of transformation of trust to the entire food system in China. The transformative potential of AFNs, as many rural sociologists have discussed (Goodman 2004, Marsden and Murdoch 2006), has yet to unfold in China.

This study also shows that within a system in which food regulatory institutions are not trusted by consumers, individual trust and organizational trust might be effective approaches to rebuild the shattered confidence in food safety. In the case of the $\mathrm{BCF}$, the reconstruction of individual trust and the development of organizational trust have conveniently met some urbanites' demand for healthy food in response to food safety crises in China. However, this does not imply that individual trust and organizational trust have necessarily replaced institutional trust. In fact, they coexist in many cases. For many customers, AFNs do not replace but partially substitute for conventional food venues. We use the term "transformation of trust" to examine the emergence of AFNs in China rather than to suggest a fundamental shift.

Finally, our analysis of the transformation of trust has theoretical implications for future social science research on issues of trust. The problem of trust is a social dilemma; however, trust is an indispensable element that glues a society together. This study associates empirical evidence with social theories of trust and proposes the concept of transformation of trust to expand the scope of research on trust. This advancement enhances understanding of the elusive notion of trust in more complex social-economic-political contexts. This perspective is different from conventional social theory research that relies on simple socioeconomic activities or laboratory experiments with artificial configurations.

We acknowledge that, in empirical settings, different types of trust are multifaceted, evolving relationships characterized by heterogeneous social structures, institutional arrangements, cultural contexts, and biophysical conditions. This study does not intend to criticize the conventional approach. In fact, the conventional approach has the merits of excluding noise and 
focusing on key variables in a controlled environment. What we propose is methodological pluralism and contextual diversification that seek to provide more comprehensive and nuanced explanations. As scholars continue to be intrigued by the origins, forms, and evolution of trust, it is also important to analyze complex outcomes and mechanisms of trust that might vary under different empirical conditions. We suggest that further research should examine discoveries of new socioeconomic phenomena; explanations for dynamics of interactions; and factors, variables, and conditions that might sustain trust and cooperation from a long-term perspective.

\section{CONCLUSION}

Trust is a key factor to understanding food safety issues and the dynamics of consumer behavior in food systems. We elaborate theories of trust in complex socioeconomic activities from a sociological perspective and emphasize an evolving process, i.e., transformation of trust, that has not been adequately studied in previous literature. We provide a case of trust in food, the Beijing Country Fair farmers' market, that vividly illustrates an important yet understudied phenomenon in which informal social mechanisms have been partially substituting for formal institutions and gradually fostering the transformation of trust in China's alternative food networks. We have shown various facets of the disruption of institutional trust and how the explosion of information has contributed to this process. We associated our first-hand data with theories of direct and indirect reciprocity and explained how individual trust between customers and vendors has been reconstructed. Finally, we uncovered two additional social conditions, endogenous rules and altruism, and elucidated how they have facilitated the development of organizational trust and the prosperity of the BCF and CSAs. By unpacking the process of trust transformation, we supplement previous social theories of trust from a dynamic and multidimensional perspective. We also provide new understandings of trust relationships and socioeconomic interactions between various stakeholders in food systems against the backdrop of the food safety crisis in China. ${ }^{[1]}$ For a more in-depth discussion on the defining characteristics of alternative food networks in China, see Si et al. 2014 and Schumilas 2014.

${ }^{[2]}$ Community-Supported Agriculture (CSA), as a critical type of alternative food network, enables a consumer to pay a farmer in advance of the growing season for a share of the harvest. The farmer promises to farm in an ecological way and typically delivers a share of harvest weekly to the customer during the season. In CSAs, customers share both the risk of agriculture and the harvest with farmers.

${ }^{[3]}$ Green food (l üse shipin) is a food quality standard in China that is lower than the organic standard. On the differences between green food, "hazard-free food" (wugonghai), and organic food in China, see Scott et al. (2014).

[4] The distrust of institutions is also enhanced by the debate centering upon the health implications and the illegal dissemination of genetically modified (GM) food. Because GM crops have been reported to be growing illegally in China, the Chinese government has been widely criticized for failing to control its spread (e.g., Jian 2014).

${ }^{[5]}$ Although there are various definitions of middle class, in this paper, we use this term to refer to "the group of urban and rural residents whose income level, within a standard time period and locality, is comparable to the middle income level for all citizens" (Wu and Yang 2006, as cited in Shi et al. 2011a:555). According to $\mathrm{Lu}$ (2010), about $23 \%$ of the population (around 300 million people) in China belonged to the middle class by the year 2010 , and that proportion is still growing. According to our interview with one market manager in April 2012, customers of the Beijing Country Fair (BCF) were mainly middle-class households who "can afford Starbucks coffee." Studies of the customers of the Little Donkey Farm (Shi et al. 2011a, b), which is a well-known vendor at the $\mathrm{BCF}$, also demonstrated a strong middle-class feature, with $71 \%$ of them reporting a monthly household income above 10,001 RMB (US\$1667), whereas the average monthly income of a middle-class family in Beijing in 2010 was 10,007 RMB (Lu 2010).

[6] In 2012, each market event generated total sales of 150,000-250,000 CNY (approximately US\$25,000-\$41,600; Shu 2012). Because of the overwhelming popularity and growing number of customers, the Beijing Country Fair expanded its single weekly market to two or three markets at different locations in Beijing.

${ }^{[7]}$ Wechat is a mobile text and voice messaging communication app developed by Chinese IT Company Tencent. As of August 2014, Wechat had 438 million active users.

Responses to this article can be read online at: http://www.ecologyandsociety.org/issues/responses. $\mathrm{php} / 7536$

\section{Acknowledgments:}

We would like to acknowledge funding from the Social Sciences and Humanities Research Council of Canada that made possible the fieldwork on which this article is based.

\section{LITERATURE CITED}

Agres, T. 2013. Despite regulatory reform, China's food safety remains problematic. Food Quality \& Safety, 15 February. [online] URL: http://www.foodquality.com/details/article/4366181/ Despite Regulatory Reform Chinas Food Safety Remains Problematic. $\underline{\text { html?tzcheck }=1}$

Axelrod, R. 1984. The evolution of cooperation. Basic Books, New York, New York, USA.

Axelrod, R., and W. D. Hamilton. 1981. The evolution of cooperation. Science 211(4489):1390-1396. http://dx.doi.org/10.1126/ $\underline{\text { science. } 7466396}$

Bachmann, R., and A. C. Inkpen. 2011. Understanding institutional-based trust building processes in inter-organizational relationships. Organization Studies 32(2):281-301. http://dx.doi. org/10.1177/0170840610397477

Beck, U. 1992. Risk society: towards a new modernity. Sage, London, UK.

Berg, L. 2004. Trust in food in the age of mad cow disease: a comparative study of consumers' evaluation of food safety in Belgium, Britain and Norway. Appetite 42(1):21-32. http://dx.doi. org/10.1016/S0195-6663(03)00112-0 
Broughton, E. I., and D. G. Walker. 2010. Policies and practices for aquaculture food safety in China. Food Policy 35:471-478. http://dx.doi.org/10.1016/j.foodpol.2010.05.007

Chen, M.-F. 2008. Consumer trust in food safety-a multidisciplinary approach and empirical evidence from Taiwan. Risk Analysis 28:1553-1569. http://dx.doi.org/10.1111/ j.1539-6924.2008.01115.x

Chen, S. 2009. Sham or shame: rethinking the China's milk powder scandal from a legal perspective. Journal of Risk Research 12(6):725-747. http://dx.doi.org/10.1080/13669870902927251

Chen, W. 2013. The effects of different types of trust on consumer perceptions of food safety: an empirical study of consumers in Beijing Municipality, China. China Agricultural Economic Review 5:43-65. http://dx.doi.org/10.1108/17561371311294757

Coleman, J. S. 1990. Foundations of social theory. Harvard University Press, Cambridge, Massachusetts, USA.

de Jonge, J., J. C. M. van Trijp, I. A. van der Lans, R. J. Renes, and L. J. Frewer. 2008. How trust in institutions and organizations builds general consumer confidence in the safety of food: a decomposition of effects. Appetite 51:311-317. http://dx.doi. org/10.1016/j.appet.2008.03.008

Diekmann, A. 2004. The power of reciprocity-fairness, reciprocity, and stakes in variants of the dictator game. Journal of Conflict Resolution 48(4):487-505. http://dx.doi. org/10.1177/0022002704265948

Edelenbos, J., and J. Eshuis. 2012. The interplay between trust and control in governance processes: a conceptual and empirical investigation. Administration \& Society 44(6):647-674. http://dx. doi.org/10.1177/0095399711413876

Ericksen, P. J. 2008. What is the vulnerability of a food system to global environmental change? Ecology and Society 13(2): 14. [online] URL: http://www.ecologyandsociety.org/vol13/iss2/ $\underline{\operatorname{art14}}$

Feagan, R. 2007. The place of food: mapping out the 'local' in local food systems. Progress in Human Geography 31(1):23-42. http://dx.doi.org/10.1177/0309132507073527

Fehr, E., and U. Fischbacher. 2003. The nature of human altruism. Nature 425(6960):785-791. http://dx.doi.org/10.1038/ nature 02043

Fehr, E., and H. Gintis. 2007. Human motivation and social cooperation: experimental and analytical foundations. Annual Review of Sociology 33:43-64. http://dx.doi.org/10.1146/annurev. $\underline{\text { soc. } 33.040406 .131812}$

Forum on Health, Environment and Development (FORHEAD). 2014. Food safety problems in China: a mapping of problems, governance and research. Social Science Research Council, Brooklyn, New York, USA. [online] URL: http://webarchive.ssrc. org/cehi/PDFs/Food-Safety-in-China-Web.pdf

Freyer, B., J. Bingen, and R. Paxton. 2014. Can multicriteria assessment tools help build trust into organic products? Ecology and Society 19(4): 5. http://dx.doi.org/10.5751/ES-06793-190405

Fritz, M., and C. Fischer. 2007. The role of trust in European food chains: theory and empirical findings. International Food and Agribusiness Management Review 10(2):141-163.
Fukuyama, F. 1995. Trust : the social virtues and the creation of prosperity. Hamish Hamilton, London, UK.

Garfinkel, H. 1963. A conception of and experiments with "trust" as a condition for stable concerted actions. Pages 187-238 in O. J. Harvey, editor. Motivation and social interaction. Ronald Press, New York, New York, USA.

Giddens, A. 1991. Modernity and self-identity: self and society in the late modern age. Stanford University Press, Stanford, California, USA.

Goodman, D. 2004. Rural Europe redux? Reflections on alternative agro-food networks and paradigm change. Sociologia Ruralis 44(1):3-16. http://dx.doi.org/10.1111/j.1467-9523.2004.00258. $\underline{\mathrm{X}}$

Goodman, D., E. M. DuPuis, and M. K. Goodman. 2012. Alternative food networks: knowledge, practice, and politics. Routledge, Abingdon, UK.

Hamilton, W. D. 1963. The evolution of altruistic behavior. American Naturalist 97(896):354-356. http://dx.doi.org/10.1086/497114

Han, J., editor. 2007. Report on food safety in China [title translated from the Chinese]. Social Sciences Academic Press, Beijing, China.

Holloway, L., R. Cox, L. Venn, M. Kneafsey, E. Dowler, and H. Tuomainen. 2006. Managing sustainable farmed landscape through 'alternative' food networks: a case study from Italy. Geographical Journal 172(3):219-229. http://dx.doi.org/10.1111/ j.1475-4959.2006.00205.X

Huang, P. C. C. 2011. China's new-age small farms and their vertical integration: agribusiness or co-ops? Modern China 37:107-134. http://dx.doi.org/10.1177/0097700410396476

International Federation of Organic Agriculture Movement. 2006. Participatory guarantee systems: case studies from Brazil, India, New Zealand, USA. International Federation of Organic Agriculture Movement, Bonn, Germany. http://www.ifoam.bio/ sites/default/files/page/files/studies book web.pdf

Jarosz, L. 2000. Understanding agri-food networks as social relations. Agriculture and Human Values 17(3):279-283. http://dx. doi.org/10.1023/A:1007692303118

Jia, C., and D. Jukes. 2013. The national food safety control system of China - a systematic review. Food Control 32(1): 236-245. http://dx.doi.org/10.1016/j.foodcont.2012.11.042

Jian, Y. 2014. Illegally grown GM crops ending up on consumers' dinner plates. Shanghai Daily, 4 March. [online] URL: http:// www.shanghaidaily.com/national/Illegally-grown-GM-crops-endingup-on-consumers-dinner-plates/shdaily.shtml

Johnson-George, C., and W. C. Swap. 1982. Measurement of specific interpersonal trust: construction and validation of a scale to assess trust in a specific other. Journal of Personality and Social Psychology 43(6):1306-1317. http://dx.doi.org/10.1037//0022-35$\underline{14.43 .6 .1306}$

Kirwan, J. 2004. Alternative strategies in the UK agro-food system: interrogating the alterity of farmers' markets. Sociologia Ruralis 44(4):395-415. http://dx.doi.org/10.1111/j.1467-9523.2004.00283. $\underline{\mathrm{X}}$ 
Kjærnes, U. 2006. Trust and distrust: cognitive decisions or social relations? Journal of Risk Research 9(8):911-932. http://dx.doi. org/10.1080/13669870601065577

Kjærnes, U. 2010. Consumer trust in food under varying social and institutional conditions. Pages 75-86 in V. Koukouliou, M. Ujevic, and O. Premstaller, editors. Threats to food and water chain infrastructure. Springer, Dordrecht, The Netherlands. http://dx. doi.org/10.1007/978-90-481-3546-2 5

Klein, J. 2009. Creating ethical food consumers? Promoting organic foods in urban Southwest China. Social Anthropology 17 (1):74-89. http://dx.doi.org/10.1111/j.1469-8676.2008.00058.x

Klein, J. A. 2013. Everyday approaches to food safety in Kunming. China Quarterly 214:376-393. http://dx.doi.org/10.1017/ $\underline{\mathrm{S} 0305741013000325}$

Lane, C., and R. Bachmann. 1998. Trust within and between organizations: conceptual issues and empirical applications. Oxford University Press, New York, New York, USA.

Levi, M., and L. Stoker. 2000. Political trust and trustworthiness. Annual Review of Political Science 3:475-507. http://dx.doi. org/10.1146/annurev.polisci.3.1.475

Li, P. J. 2009. Exponential growth, animal welfare, environmental and food safety impact: the case of China's livestock production. Journal of Agricultural and Environmental Ethics 22:217-240. http://dx.doi.org/10.1007/s10806-008-9140-7

Lindgreen, A. 2003. Trust as a valuable strategic variable in the food industry: different types of trust and their implementation. British Food Journal 105(6):310-327. http://dx.doi. org/10.1108/00070700310481694

Liu, P. 2010. Tracing and periodizing China's food safety regulation: a study on China's food safety regime change. Regulation \& Governance 4:244-260. http://dx.doi.org/10.1111/ j.1748-5991.2010.01078.x

Lobb, A. E., M. Mazzocchi, and W. B. Traill. 2007. Modelling risk perception and trust in food safety information within the theory of planned behaviour. Food Quality and Preference 18 (2):384-395. http://dx.doi.org/10.1016/j.foodqual.2006.04.004

Lorenz, E. H. 1988. Neither friends nor strangers: informal networks of subcontracting in French industry. Pages 194-210 In D. Gambetta, editor. Trust: making and breaking cooperative relations. Oxford University Press, Oxford, UK.

Lu, X. Y. 2010. Contemporary Chinese social structure. Social Science Academic Press, Beijing, China.

Lu, Y., A. Jenkins, R. C. Ferrier, M. Bailey, I. J. Gordon, S. Song, J. Huang, S. Jia, F. Zhang, X. Liu, Z. Feng, and Z. Zhang. 2015. Addressing China's grand challenge of achieving food security while ensuring environmental sustainability. Science Advances 1 (1):e1400039 http://dx.doi.org/10.1126/sciadv.1400039

Mailath, G. J., and L. Samuelson. 2006. Repeated games and reputations: long-run relationships. Oxford University Press, New York, New York, USA. http://dx.doi.org/10.1093/acprof: oso/9780195300796.001.0001

Marsden, T., and A. Franklin. 2013. Replacing neoliberalism: theoretical implications of the rise of local food movements. Local
Environment 18(5):636-641. http://dx.doi.org/10.1080/13549839.2013 .797157

Marsden, T., and J. Murdoch 2006. Between the local and the global: confronting complexity in the contemporary agri-food sector. Elsevier, Oxford, UK.

Mayer, R. C., J. H. Davis, and F. D. Schoorman. 1995. An integrative model of organizational trust. Academy of Management Review 20(3):709-734. http://dx.doi.org/10.2307/258792

McDonald, M., and S. Iyer. 2008. Skillful means: the challenges of China's encounter with factory farming. Brighter Green, New York, New York, USA. [online] URL: http://www.brightergreen. org/files/brightergreen china print.pdf

Milestad, R., L. Westberg, U. Geber, and J. Björklund. 2010. Enhancing adaptive capacity in food systems: learning at farmers' markets in Sweden. Ecology and Society 15(3): 29. [online] URL: http://www.ecologyandsociety.org/vol15/iss3/art29/

Mishler, W., and R. Rose. 2001. What are the origins of political trust? Testing institutional and cultural theories in postcommunist societies. Comparative Political Studies 34(1):30-62. http://dx.doi.org/10.1177/0010414001034001002

Mohtashemi, M., and L. Mui. 2003. Evolution of indirect reciprocity by social information: the role of trust and reputation in evolution of altruism. Journal of Theoretical Biology 223 (4):523-531. http://dx.doi.org/10.1016/S0022-5193(03)00143-7

Mol, A. P. J. 2014. Governing China's food quality through transparency: a review. Food Control 43:49-56. http://dx.doi. org/10.1016/j.foodcont.2014.02.034

Ng, C. N., R. Y. Wang, and T. J. Zhao. 2013. Joint effects of asymmetric payoff and reciprocity mechanisms on collective cooperation in water sharing interactions: a game theoretic perspective. PLoS One 8(8):e73793. http://dx.doi.org/10.1371/ journal.pone.0073793

Nooteboom, B., H. Berger, and N. G. Noorderhaven. 1997. Effects of trust and governance on relational risk. Academy of Management Journal 40(2):308-338. http://dx.doi.org/10.2307/256885

Nowak, M. A. 2006. Five rules for the evolution of cooperation. Science 314(5805):1560-1563. http://dx.doi.org/10.1126/science.1133755

Nowak, M. A. 2012. Evolving cooperation. Journal of Theoretical Biology 299:1-8. http://dx.doi.org/10.1016/j.jtbi.2012.01.014

Pei, X., A. Tandon, A. Alldrick, L. Giorgi, W. Huang, and R. Yang. 2011. The China melamine milk scandal and its implications for food safety regulation. Food Policy 36(3):412-420. http://dx.doi.org/10.1016/j.foodpol.2011.03.008

People's Daily. 2012. How to win consumers' trust in organic food? [title translated from the Chinese]. People's Daily, 18 July. [online] URL: http://news.ifeng.com/gundong/detail 2012 07/18/16100628 0. $\underline{\text { shtml. }}$

Putnam, R. D. 1993. Making democracy work: civic traditions in modern Italy. Princeton University Press, Princeton, New Jersey, USA.

Putnam, R. D. 1995. Tuning in, tuning out: the strange disappearance of social capital in America. Political Science and Politics 28(4):664-683. http://dx.doi.org/10.2307/420517 
Rothstein, B. 2005. Social traps and the problem of trust. Cambridge University Press, Cambridge, UK. http://dx.doi. org/10.1017/CBO9780511490323

Rousseau, D. M., S. B. Sitkin, R. S. Burt, and C. Camerer. 1998. Not so different after all: a cross-discipline view of trust. Academy of Management Review 23(3):393-404. http://dx.doi.org/10.5465/ AMR.1998.926617

Schneider, M. 2014. What, then, is a Chinese peasant? Nongmin discourses and agroindustrialization in contemporary China. Agriculture and Human Values: 1-16. http://dx.doi.org/10.1007/ s10460-014-9559-6

Schoorman, F. D., R. C. Mayer, and J. H. Davis. 2007. An integrative model of organizational trust: past, present, and future. Academy of Management Review 32(2):344-354. http://dx. doi.org/10.5465/AMR.2007.24348410

Schuetz, A. 1945. On multiple realities. Philosophy and Phenomenological Research 5(4):533-576. http://dx.doi. org/10.2307/2102818

Schumilas, T. 2014. Alternative food networks with Chinese characteristics. Dissertation. University of Waterloo, Ontario, Canada.

Scott, S., Z. Si, T. Schumilas, and A. Chen. 2014. Contradictions in state- and civil society-driven developments in China's ecological agriculture sector. Food Policy 45:158-166. http://dx. doi.org/10.1016/j.foodpol.2013.08.002

Shao, X., and H. Yang. 2014. Organic vegetable faces trust crisis [title translated from the Chinese]. Economic Information Daily, 22 August. [online] URL: http://finance.sina.com.cn/consume/ puguangtai/20140822/094920090600.shtml

Sharma, S., B. Lilliston, C. Pi, Z. Rou, S. Horowitz. 2014. Fair or fowl? Industrialization of poultry production in China. Institute for Trade and Agriculture Policy, Minneapolis, Minnesota, USA. [online] URL: http://www.iatp.org/documents/fair-or-fowlindustrialization-of-poultry-production-in-china

Shi, Y. 2012. Farming in the US. SDX Joint Publishing, Beijing, China.

Shi, Y., C. Cheng, P. Lei, T. Wen, and C. Merrifield. 2011a. Safe food, green food, good food: Chinese Community Supported Agriculture and the rising middle class. International Journal of Agricultural Sustainability 9(4):551-558. http://dx.doi. org/10.1080/14735903.2011.619327

Shi, Y., C. Cheng, P. Lei, Y. Zhu, Y. Jia, and T. Wen. $2011 b$. Correlation analysis of ecological urban agriculture development and the rise of urban middle class: a participatory study based on the operation of Little Donkey Farm CSA [title translated from the Chinese]. Guizhou Social Sciences 254(2):55-60.

Shu, Q. 2012. Beijing Farmers' Market: an attempt to build the "food community" [title translated from the Chinese]. Wall Street Journal (Chinese version), 29 October. [online] URL: http://cn. wsj.com/gb/20121029/TRV082620.asp

Si, Z., T. Schumilas, and S. Scott. 2014. Characterizing alternative food networks in China. Agriculture and Human Values 32 (2):299-313. http://dx.doi.org/10.1007/s10460-014-9530-6
Si, Z. Z. 2015. Alternative food networks and rural development initiatives in China: characterization, contestations and interactions. Dissertation. University of Waterloo, Ontario, Canada.

Sigmund, K. 2012. Moral assessment in indirect reciprocity. Journal of Theoretical Biology 299:25-30. http://dx.doi. org/10.1016/j.jtbi.2011.03.024

Sonnino, R., and T. Marsden. 2006. Beyond the divide: rethinking relationships between alternative and conventional food networks in Europe. Journal of Economic Geography 6(2):181-199. http:// dx.doi.org/10.1093/jeg/lbi006

Tam, W. K., and D. L. Yang. 2005. Food safety and the development of regulatory institutions in China. Asian Perspective 29:5-36.

Uslaner, E. M. 2002. The moral foundations of trust. Cambridge University Press, New York, New York, USA. http://dx.doi. org/10.1017/CBO9780511614934

Veeck, A., H. Yu, and A. C. Burns. 2010. Consumer risks and new food systems in urban China. Journal of Macromarketing 30 (3):222-237. http://dx.doi.org/10.1177/0276146710372221

Wang, D. B., and X. S. Hu. 2011. The government's reputation is abused by food examination institutions [title translated from the Chinese]. [online] URL: http://finance.jri.com.cn/2011/04/3012509865419. $\underline{\text { shtml }}$

Wang, Z., Y. Mao, and F. Gale. 2008. Chinese consumer demand for food safety attributes in milk products. Food Policy 33 (1):27-36. http://dx.doi.org/10.1016/j.foodpol.2007.05.006

Welsh, J., and R. MacRae. 1998. Food citizenship and community food security: lessons from Toronto, Canada. Canadian Journal of Development Studies 19(4):237-255. http://dx.doi. org/10.1080/02255189.1998.9669786

Whatmore, S., P. Stassart, and H. Renting. 2003. What's alternative about alternative food networks? Environment and Planning A 35(3):389-391. http://dx.doi.org/10.1068/a3621

Wiskerke, J. S. C. 2009. On places lost and places regained: reflections on the alternative food geography and sustainable regional development. International Planning Studies 14 (4):369-387. http://dx.doi.org/10.1080/13563471003642803

Yan, Y. 2012. Food safety and social risk in contemporary China. Journal of Asian Studies 71(3):705-729. http://dx.doi.org/10.1017/ $\underline{\mathrm{S} 0021911812000678}$

Yang, G. 2013. Contesting food safety in the Chinese media: between hegemony and counter-hegemony. China Quarterly 214:337-355. http://dx.doi.org/10.1017/S0305741013000386

Zucker, L. G. 1986. Production of trust: institutional sources of economic structure, 1840-1920. Research in Organizational Behavior 8:53-111. 